\title{
Natriuretic Peptides and Troponin I Do Not Predict Chemotherapy- Induced Cardiac Toxicity
}

Katja Jungandreas ${ }^{1 *}$, Alexander Vogt ${ }^{1}$, Wieland Voigt ${ }^{2}$, Karin Jordan ${ }^{2}$, Hans-Georg Strau ${ }^{3}$, Christoph Thomssen ${ }^{3}$, Henning Ebelt ${ }^{1}$, Karl Werdan ${ }^{1}$, Jürgen Schwamborn ${ }^{4}$ and Axel Schlitt ${ }^{1,5}$

${ }^{1}$ Department of Medicine III, University Clinic of the Martin Luther-University Halle-Wittenberg, Germany ${ }^{2}$ Department of Medicine IV, University Clinic of the Martin Luther-University Halle-Wittenberg, Germany ${ }^{3}$ Department of Gynaecology, University Clinic of the Martin Luther-University Halle-Wittenberg, Germany

${ }^{4}$ Department of Oncology, Paracelsus-Harz-Clinic Bad Suderode, Germany

${ }^{5}$ Department of Cardiology, Paracelsus-Harz-Clinic Bad Suderode, Germany

\begin{abstract}
Background/Aims: Cytostatics and human antibodies are successfully being used to treat oncological diseases. Despite the beneficial effects of these potent drugs, cardiotoxicity represents one of the most relevant side effects and limits their usage. It is very important to detect cardiotoxicity at an early stage particular in patients under curative chemotherapy to avoid long-term side effects and impairment of quality of life. The aim of this prospective study was to investigate the value of natriuretic peptides and troponin for early detection of cardiotoxicity.
\end{abstract}

Patients and Methods: In this single-center study, 99 cancer patients under treatment with anthracyclines, taxanes, and/or trastuzumab were prospectively included. Clinical examination, echocardiography, and blood sampling (brain natriuretic peptide (BNP), N-terminal-proBNP, and troponin I) were performed at baseline and at 3 and 12 months, respectively. Cardiotoxicity was defined as clinical or echocardiographic signs of heart failure as defined by an increment in New York Heart Association (NYHA) class by more than one and a decline in left ventricular ejection fraction (LVEF) depending on baseline situation.

Results: During the 12-month follow-up, 27 patients presented with at least one predefined endpoint. Neither BNP, nor NT-proBNP, nor troponin I was related to the incidence of cardiotoxicity as defined by the combined endpoint. In post-hoc analysis a significant association between an increasing NYHA stage and a decrease in LVEF was found (negative predictive value of $91 \%$ ).

Conclusion: The occurrence of cardiotoxicity could not be detected either by natriuretic peptides or troponin. However, we hypothesize that an increase of more than one NYHA stage as a marker for dyspnea may be an indicator of cardiotoxicity.

\section{Background}

With modern treatment modalities, prognosis and quality of life have been improved for people with malignant diseases, especially with respect to the decrease in potential side effects such as nausea/emesis and hematotoxicity. However, one of the most serious side effects, cardiotoxicity, still represents an important problem. Anti-cancer drugs related to cardiac toxicity are, for example, anthracyclines, taxanes, and antibodies such as trastuzumab [1]. These drugs are widely used and indispensable in the therapy of lymphoma, leukemia, and breast carcinoma [2].

Anthracyclines have been used to treat cancer since 1960. Typical toxic side effects are leukopenia, thrombopenia, and anemia. Another important side effect is cardiotoxicity. This usually becomes apparent mostly months to years after cessation of chemotherapy and can be irreversible [3]. When cardiotoxicity develops at a later stage under anthracycline treatment, cardiomyopathy with progressive ventricle dilatation is found most frequently [3].

Cardiotoxicity associated with anthracyclines depends on the accumulated dose, clinical history of cardiac diseases, and the patient's general condition, as well as a high single dose, short administration times, and age $[3,4]$. Children and elderly people over 65 years of age are at a higher risk for cardiomyopathy [5].

Furthermore, taxanes and the human antibody trastuzumab are also potentially cardiotoxic [6,7]. The risk for cardiotoxicity under treatment with these drugs is estimated to be $0.5 \%$ to $7 \%$, as suggested by different authors $[5,8]$.
The combination of potentially cardiotoxic drugs substantially increases the probability of cardiotoxicity; indeed, the combination of trastuzumab and anthracyclines in the treatment of breast cancer increases this risk up to $27 \%$ [7].

The problem of the early and late side effects such as cardiotoxicity caused by anti-cancer drugs is becoming increasingly socioeconomically relevant not only because of the rising survival rates of cancer [2]. It is important to identify cardiac symptoms and treat cardiotoxicity at an early stage. Echocardiography is the gold standard for detecting side effects of cancer therapy such as systolic and diastolic heart failure [9]. Basically, echocardiography should be performed regularly at the beginning and during treatment. However, echocardiography is time consuming; furthermore, the interpretation is investigator dependent.

*Corresponding author: Katja Jungandreas, Department of Medicine III University Clinic of the Martin Luther-University Halle-Wittenberg, Ernst-Grube-Str. 40, 06120 Halle, Germany, Tel: +49 345557 4951; Fax: +49 345557 4951; E- mail: Katja.Jungandreas@vivantes.de

Received December 31, 2013; Accepted January 15, 2014; Published January 22, 2014

Citation: Jungandreas K, Vogt A, Voigt W, Jordan K, Strauß HG (2014) Natriuretic Peptides and Troponin I Do Not Predict Chemotherapy-Induced Cardiac Toxicity. J Cardiovasc Dis Diagn 2: 140. doi:10.4172/2329-9517.1000140

Copyright: ( 2014 Jungandreas K, et al. This is an open-access article distributed under the terms of the Creative Commons Attribution License, which permits unrestricted use, distribution, and reproduction in any medium, provided the original author and source are credited. 
Thus, new and easy methods such as detecting natriuretic peptides and troponin seem to represent attractive alternatives.

The natriuretic peptides BNP and NT-proBNP are successfully used in diagnosing heart failure. The cardiac structure protein troponin is a potential marker for myocardial damage and is, in addition to electrocardiography, the gold standard for diagnosing myocardial infarction [10].

Thus, it can be assumed that BNP and NT-proBNP as well as troponin could also reflect the myocardial damage caused by oncological drugs at an early stage.

However, the debate is still ongoing as concerns the value of BNP, NT-proBNP and troponin to detect cardiac toxicity under anthracycline treatment [10].

\section{Methods}

\section{Baseline variables}

A total of 110 cancer patients were identified during treatment in the Department of Medicine and Department of Gynecology of the University Hospital Halle (Saale). Main inclusion criteria were treatment with anthracyclines, taxanes, and/or trastuzumab for oncological disease and an age above 18 years. In total 99 patients were included; the main exclusion criterion was unwillingness to participate in the study.

The study was approved by the ethics committee of the Martin Luther-University Halle-Wittenberg. Patients in other clinical studies were not excluded. The patient's results were not affected from other studies.

After receiving written informed consent, clinical examination, clinical history, transthoracic echocardiography, and blood sampling to detect of BNP, NT-proBNP, and troponin I were performed at baseline and also during the follow-up period after 3 and 12 months, respectively.

Cardiotoxicity was considered as a combined endpoint. First of all this predefined combined endpoint consisted of progressive dyspnea as clinical signs of heart failure. We objectify the subjective sign dyspnea on exertion by an increment in NYHA stage by more than one. Secondly the predefined endpoint include the decline in LVEF by more than $20 \%$ (absolute) if LVEF> 50\% at study entry, decline in LVEF by more than $10 \%$ (absolute) if LVEF $<50 \%$ during follow-up, and decline in LVEF by more than 5\% (absolute) if LVEF was less than $50 \%$ at inclusion. Likewise were including local myocardial movement disorders which were not operated in LVEF.

The kind of the treatment scheme depended on disease and risk factors such as age and genetic alterations. The most common schemes were FEC (5-fluorouracil, epirubicin and cyclophosphamide) and ddETC (epirubicin, paclitaxel, and cyclophosphamide) for the treatment of breast cancer. For the treatment of non-Hodgkin lymphoma, the R-CHOP (cyclophosphamide, vincristine, prednisolone, adriamycin, and rituximab) scheme was mostly used.

Echocardiography was performed according to the standards at our university clinic (according to Buck et al. [9]) by a single sonographer which were not blinded to prior results. Additionally another cardiologist controlled the results. The parameters for early diastolic mitral annulus velocity (E'), the ratio of the speed of early left ventricular filling (E) to E', and also the ratio of early atrial left ventricular filling
E/A were taken as the definition of diastolic dysfunction according to Erbel et al. [11].

\section{Statistical analyses}

Continuous variables were described as mean and standard deviation, skewed variables as median and 25\%/75\% quartiles. Categorical variables were documented as percentages. For comparison of metric, normally distributed variables, the T-test was applied. MannWhitney U-test was used to compare skewed variables. For normally distributed, categorical variables, the chi-squared test was employed. Survival analyses included Kaplan-Meier analyses with log-rank test. $\mathrm{P}$-values $<0.05$ were considered as significant. Statistical analyses were performed using SPSS ${ }^{\circ}$-software (SPSS Inc., Chicago, Illinois, USA).

\section{Results}

\section{Baseline data}

Baseline data are depicted in Table 1 . Here, $49.5 \%$ of patients were recruited at Department of Gynecology and $50.5 \%$ at the Department of Internal Medicine IV (hematology-oncology) of the University Hospital Halle (Saale). Of the patients, $68.7 \%$ were women; the mean age was $56.1 \pm 14.0$ years. 37 of the 99 patients $(37,4 \%)$ received a thoracic radiation treatment.

Patients without an endpoint presented with a significantly lower LVEF at the time of study entry than patients with an endpoint $(\mathrm{p}=0.035$, shown in Table 1). Furthermore, the E/A ratio was significantly elevated in patients with an endpoint $(\mathrm{p}=0.005$, shown in Table 1). However, non significant differences between the groups were observed for $\mathrm{E}^{\prime}$ $(\mathrm{p}=0.073)$ and $\mathrm{E} / \mathrm{E}^{\prime}(\mathrm{p}=0.094)$ as other parameters of diastolic function.

\section{Incidence of single endpoints (absolute)}

As seen in figure 1 , a total of $28.3 \%$ of patients $(n=28)$ from the entire population suffered from the combined endpoint. Most of them had dyspnea, $21.1 \%(\mathrm{n}=21)$, followed by a decrease in LVEF of $20 \%$ (absolute) and of $10 \%$ (absolute) in $11.1 \%$ of patients $(n=11)$.

\section{Overall development of BNP and NT-proBNP}

Figure 2 shows the BNP values at baseline, 3 months, and 12 months, respectively, in comparison with patients with and without an endpoint during the follow-up.

Both groups showed a wide variance of values and nearly all were in the normal range of below $100 \mathrm{pg} / \mathrm{ml}$. Comparing the groups over time, we did not find significant elevations in median BNP values. In the cohort without cardiac dysfunction, the median values increased from $34.5 \mathrm{pg} / \mathrm{ml}$ and up to $39.0 \mathrm{pg} / \mathrm{ml}$ at 3 months and $41.0 \mathrm{pg} / \mathrm{ml}$ at 12 months. The group of patients who reached the combined endpoint had BNP values which had not statistically increased, from $23.0 \mathrm{pg} / \mathrm{ml}$ at baseline to $30.0 \mathrm{pg} / \mathrm{ml}$ at 3 months, and $41.0 \mathrm{pg} / \mathrm{ml}$ at 12 months.

Figures 3 and 4 show NT-proBNP levels at baseline, and after 3 and 12 months, respectively. All values were within the locally level of defined normal range, except for men over 49 years of age. However, the number of cases in this group was small at $n=2$. Comparison of the groups concerning NT-proBNP levels over the follow-up period and among each other showed no significant differences.

Comparing BNP and NT-proBNP levels before and after decrease in LVEF no significant differences were observed $(\mathrm{p}=0.655$ and $\mathrm{p}=0.556$, respectively). 
Citation: Jungandreas K, Vogt A, Voigt W, Jordan K, Strauß HG, et al. (2014) Natriuretic Peptides and Troponin I do not Predict ChemotherapyInduced Cardiac Toxicity. J Cardiovasc Dis Diagn 2: 140. doi:10.4172/2329-9517.1000140

Page 3 of 7

\begin{tabular}{|c|c|c|c|c|}
\hline \multirow{2}{*}{ Variable } & \multirow{2}{*}{ all $(n=99)$} & \multicolumn{2}{|r|}{$\square$} & \multirow{2}{*}{$\mathbf{p}$} \\
\hline & & yes $(n=28)$ & no $(n=71)$ & \\
\hline Age, $M \pm S D$ & $56.1 \pm 14.0$ & $52.0 \pm 16.2$ & $57.8 \pm 12.8$ & 0.064 \\
\hline Male, n (\%) & $31(31.3)$ & $7(25.0)$ & $24(33.8)$ & \\
\hline Active smoker, n (\%) & $17(18.5)$ & $4(16.7)$ & $13(19.1)$ & 0.790 \\
\hline Diabetes mellitus, $\mathrm{n}(\%)$ & $19(19.2)$ & $5(17.9)$ & $14(19.7)$ & 0.671 \\
\hline Artiell hypertension, $\mathrm{n}(\%)$ & $57(57.6)$ & $14(50.0)$ & $43(60.6)$ & 0.338 \\
\hline Known coronary heart disease, $\mathrm{n}(\%)$ & $5(5.1)$ & $1(3.6)$ & $4(5.7)$ & 0.663 \\
\hline Body mass index, $\mathrm{M} \pm \mathrm{SD}$ & $27.07 \pm 5.6$ & $27.77 \pm 6.0$ & $26.79 \pm 5.7$ & 0.428 \\
\hline Systolic blood pressure, $\mathrm{mmHG}, \mathrm{M} \pm \mathrm{SD}$ & $129.12 \pm 18.6$ & $124.5 \pm 18.3$ & $131.0 \pm 18.6$ & 0.120 \\
\hline Diasystolic blood pressure, $\mathrm{mmHG}, \mathrm{M} \pm \mathrm{SD}$ & $78.12 \pm 12.2$ & $77.61 \pm 9.8$ & $78.33 \pm 13.1$ & 0.792 \\
\hline Heart rate, $M \pm S D$ & $77.05 \pm 14.0$ & $75.11 \pm 10.8$ & $77.81 \pm 15.1$ & 0.400 \\
\hline Breast cancer, $\mathrm{n}(\%)$ & $41(41.4)$ & $15(53.6)$ & $26(36.6)$ & 0.126 \\
\hline Non-Hodgkin lymphoma, n (\%) & $22(22.2)$ & $3(10.7)$ & $19(26.8)$ & 0.085 \\
\hline Anthracyclines, n (\%) & $84(84.8)$ & $23(82.1)$ & $61(85.9)$ & 0.637 \\
\hline Taxanes, n (\%) & $45(45.5)$ & $15(53.6)$ & $30(42.3)$ & 0.308 \\
\hline Trastuzumab, n (\%) & $8(8.1)$ & $3(10.7)$ & $5(7.0)$ & 0.546 \\
\hline $\begin{array}{c}\text { Ejection fraction (\%), } \\
M(25 \mathrm{Q} / 75 \mathrm{Q})\end{array}$ & $59.8(55.4 / 64.1)$ & $63.1(55.6 / 67.5)$ & $58.7(55.2 / 62.4)$ & 0.035 \\
\hline Tei-index, $\mathrm{M} \pm \mathrm{SD}$ & $0.44 \pm 0.25$ & $0.47 \pm 0.21$ & $0.43 \pm 0.26$ & 0.675 \\
\hline $\mathrm{E} / \mathrm{A}, \mathrm{M}(25 \mathrm{Q} / 75 \mathrm{Q})$ & $0.97(0.8 / 1.2)$ & $1.12(0.9 / 1.4)$ & $0.88(0.8 / 1.2)$ & 0.005 \\
\hline E/E', M (25Q/75Q) & $9.15(7.5 / 11.8)$ & $8.45(6.4 / 10.5)$ & $9.78(7.6 / 12.0)$ & 0.094 \\
\hline$E^{\prime}(\mathrm{cm} / \mathrm{s}), M \pm S D$ & $8.11 \pm 2.54$ & $9.16 \pm 2.83$ & $7.83 \pm 2.41$ & 0.073 \\
\hline TAPSE $(\mathrm{cm}), \mathrm{M} \pm \mathrm{SD}$ & $2.24 \pm 0.46$ & $2.28 \pm 0.21$ & $2.23 \pm 0.5$ & 0.774 \\
\hline Creatinine, mmol/l, M (25Q/75Q) & $69.0(60.0 / 86.0)$ & $68.5(54.0 / 80.3)$ & $69.3(60.4 / 89.5)$ & 0.291 \\
\hline CRP, mg/dl, M (25Q/75Q) & $7.0(5.0 / 26.4)$ & $5.85(5.0 / 11.7)$ & $7.13(5.1 / 29.2)$ & 0.362 \\
\hline Hemoglobin, $\mathrm{mmol} / \mathrm{l}, \mathrm{M} \pm \mathrm{SD}$ & $7.58 \pm 1.34$ & $7.49 \pm 1.35$ & $7.61 \pm 1.35$ & 0.699 \\
\hline Troponin I, ng/ml, M (25Q/75Q) & $0.03(0.02 / 0.04)$ & $0.024(0.017 / 0.034)$ & $0.028(0.017 / 0.041)$ & 0.431 \\
\hline BNP, pg/ml, M (25Q/75Q) & $41.0(15.5 / 100.5)$ & $31.33(14.62 / 78.5)$ & $44.0(18.0 / 111.0)$ & 0.316 \\
\hline NT-proBNP, mg/l, M (25Q/75Q) & $143.05(68.78 / 458.2)$ & $88.21(44.44 / 252.0)$ & $171.35(85.01 / 524.7)$ & 0.074 \\
\hline
\end{tabular}

Table 1: Baseline, echocardiographic, and laboratory parameters.

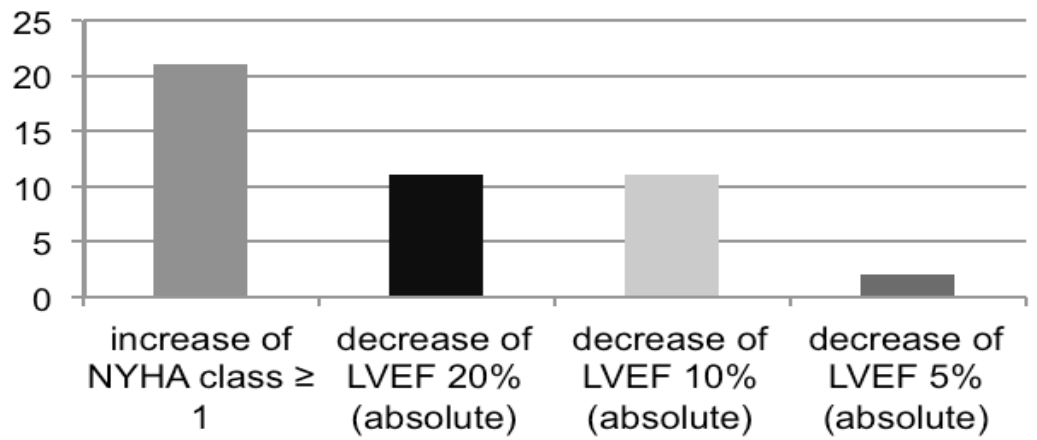

Figure 1: Incidence of the endpoints (absolute).

\section{Post -hoc analysis: dyspnea as a clinical marker for cardiotoxicity}

Table 2 shows the results of the post hoc analysis. Of the 99 patients, dyspnea progressed by more than one NYHA stage during the followup period of 12 months in $21(21.1 \%)$. In $9(42.9 \%)$ of these patients a decrease in LVEF could be observed. Within the group of patients in whom LVEF decreased (16 patients, $16.2 \%$ of the total patient group), $56.3 \%$ (9 patients) showed clinical symptoms. Of 78 patients who did not report any progression of clinical symptoms, LVEF did not decline in 71 . Thus, for patients who did not report any progression of the symptoms of heart failure under treatment with chemotherapeutics the negative predictive value is $91.0 \%(\mathrm{p}<0.001$ at chi-square test).

\section{Discussion}

Early detection of malignant diseases and improvements in medical therapy has increased the long-term survival of patients with malignant diseases. Chemotherapeutics such as anthracyclines and taxanes are being used more often and represent an indispensable component of modern oncological therapy. Unfortunately, however, most of these substances have potentially cardiotoxic side effects. Therefore, the benefits of their therapeutic use must to be weighed against the side effects, and the optimal therapy regimen needs to be chosen carefully. Furthermore, in order to reduce the consequences of cardiotoxicity it is necessary to detect these side effects as early as possible.

Echocardiography is the noninvasive gold standard for detecting 


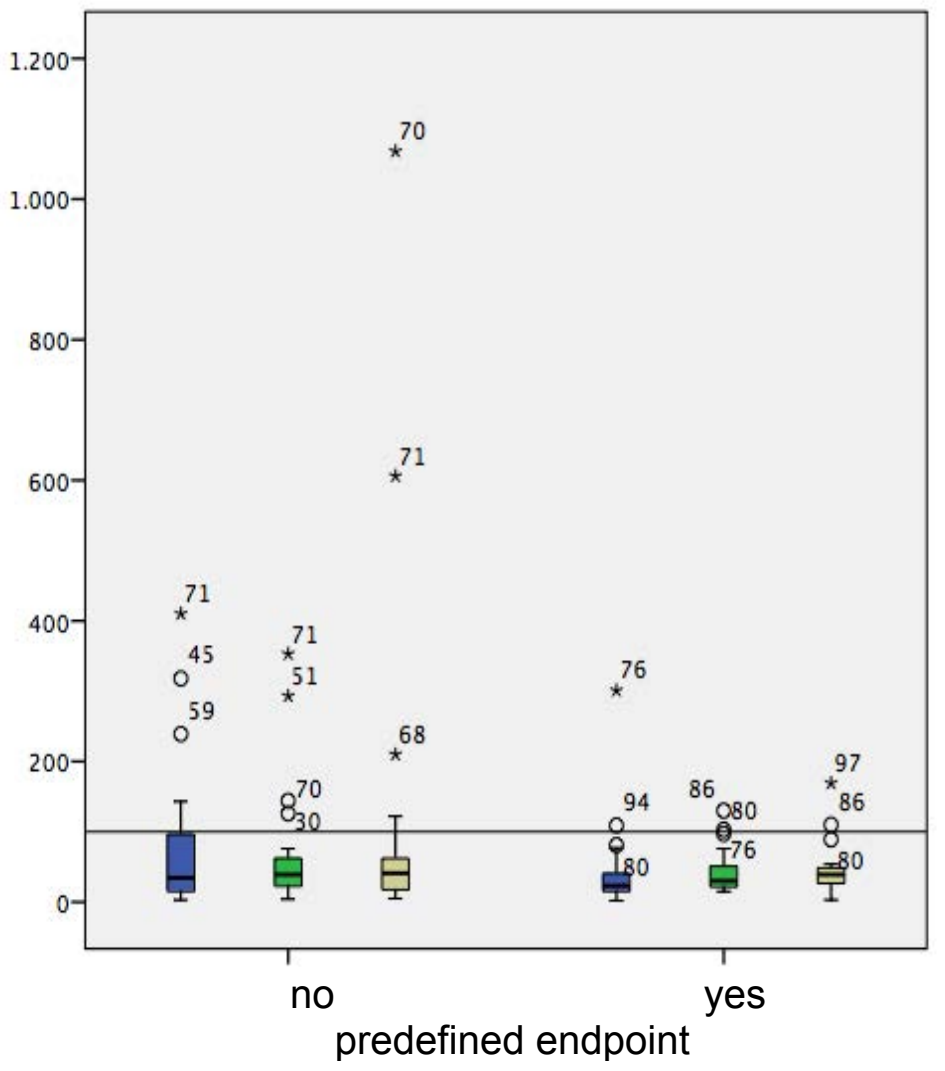

- Baseline

"Follow-up 3 months

"Follow-up 12 months

(pg/ml, standard values $100 \mathrm{pg} / \mathrm{ml}$ (horizontal line))

Figure 2: BNP comparison of in patients with or without predefined endpoint

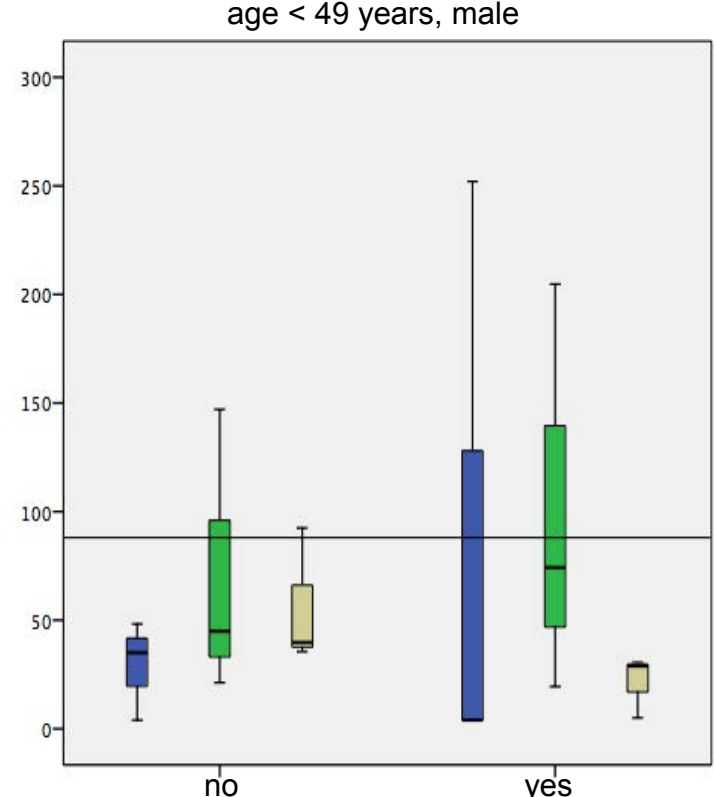

A

predefined endpoint

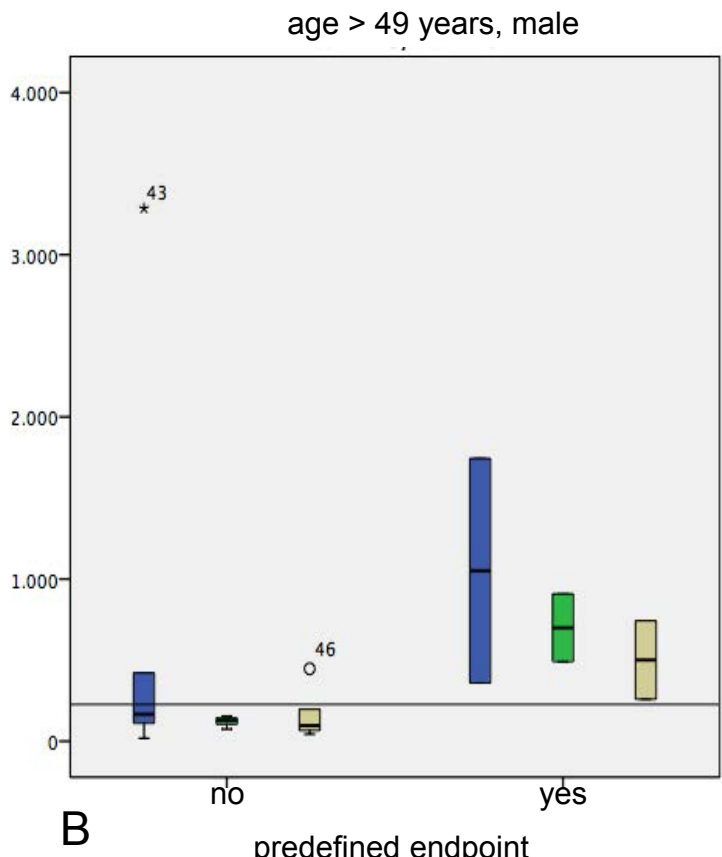

- Baseline

-Follow-up 3 months

"Follow-up 12 months

( $\mathrm{ng} / \mathrm{ml}$, standard values horizontal line; $\mathrm{p}=$ not significant comparing the variables over time and comparing the groups among each other)

Figure 3: Age-adjusted NT-proBNP: comparison of male patients with or without predefined endpoint. 
age $<49$ years, female

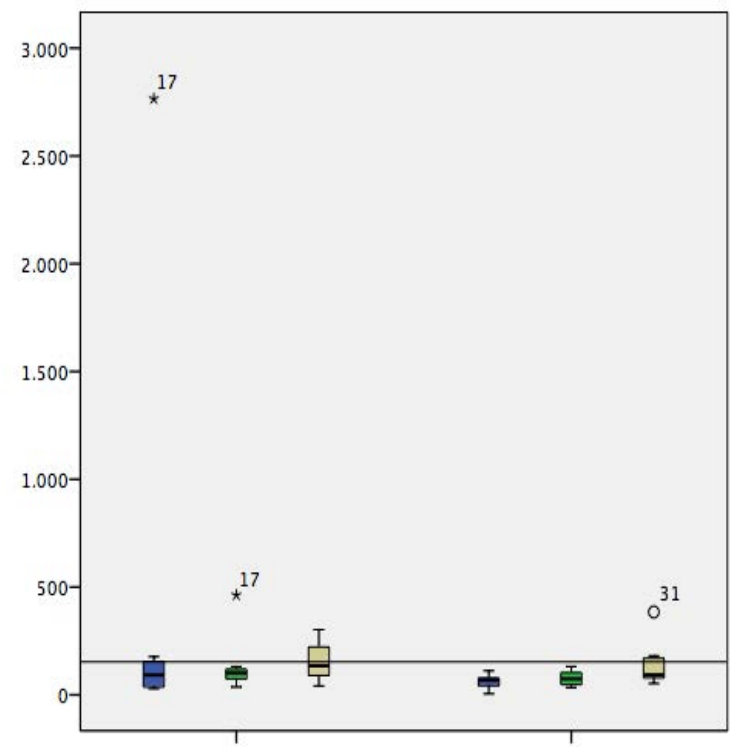

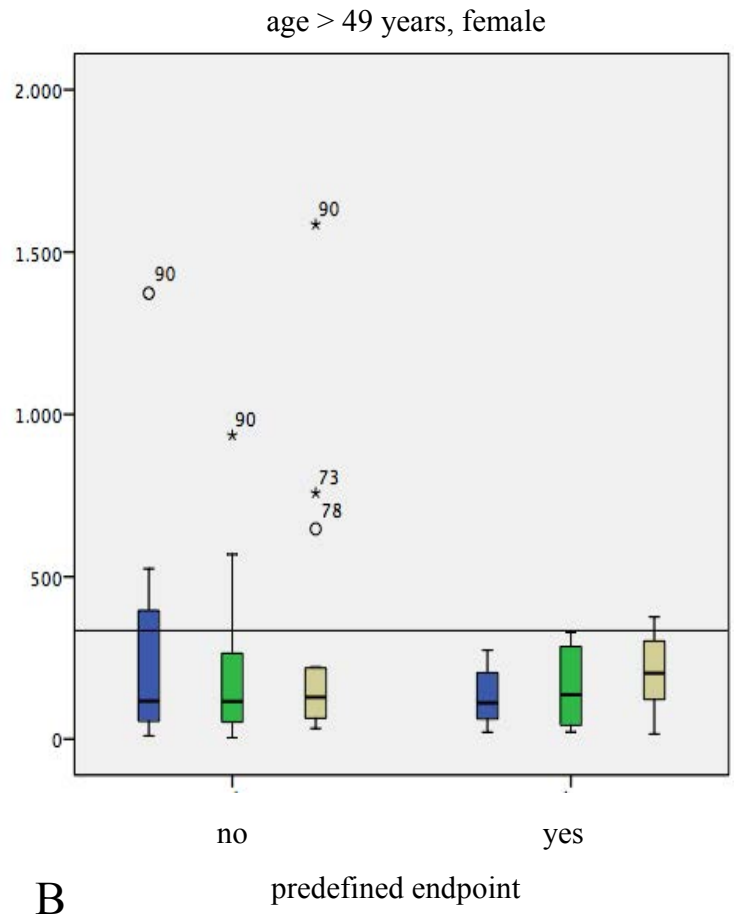

- Baseline

"Follow up 3 month

Follow up 12 month

no
A predefined endpoint yes

( $\mathrm{ng} / \mathrm{ml}$, standard values horizontal line; $\mathrm{p}=$ not significant comparing the variables over the time and comparing the groups among each other)

Figure 4: Age-adjusted NT-proBNP: comparison of female patients with or without predefined endpoint.

\begin{tabular}{|c|c|c|c|c|}
\hline & & \multicolumn{2}{|c|}{ decrease in LVEF } & \multirow[b]{2}{*}{ all } \\
\hline & & no & yes & \\
\hline \multirow{3}{*}{ increase NYHA-class $\geq 1$} & no & $71(91.0 \%)$ & $7(9.0 \%)$ & $78(100 \%)$ \\
\hline & yes & $12(57.1 \%)$ & $9(42.9 \%)$ & $21(100 \%)$ \\
\hline & all & $83(83.8 \%)$ & $16(16.2 \%)$ & $99(100 \%)$ \\
\hline
\end{tabular}

Table 2: Comparison of decrease in LVEF and increase in NYHA-stage during follow-up.

cardiac toxicity. It is easy to perform; however, the results show an examiner-dependent variability and the procedure is relatively timeconsuming.

\section{BNP and NT-proBNP}

BNP and NT-proBNP are established markers of heart failure which can be quickly obtained by standardized laboratory methods. Both natriuretic peptides correlate with the clinical severity of heart failure equal to NYHA stage. Therefore, it seems likely that it would be useful to determine BNP and NT-proBNP levels to detect cardiac toxicity. Some previous studies have verified that natriuretic peptides inversely correlate with left ventricular function and are useful subclinical markers for cardiotoxicity [12-18]. However, these findings could not be convincingly confirmed by more recent studies. Dodos et al. (2008) detected a significant reduction in systolic left ventricular function, but this was not associated with a significant increase in NT-proBNP. Of the 100 patients receiving anthracycline-based chemotherapy NT-proBNP increased in $15.3 \%$, but without cardiac dysfunction during 1-year follow-up [19]. Pichon et al. (2005) found a correlation between BNP values and the dose of anthracyclines in 12 patients, but no significant correlation with LVEF [20]. Daugaard et al. (2005, 107 patients treated with anthracyclines) and Sawaya et al. (2011, 43 patients receiving anthracyclines and trastuzumab, follow-up after 3 and 6 months) also came to the conclusion that BNP and NT-
proBNP cannot clearly predict cardiac toxicity $[21,22]$. They therefore concluded that natriuretic peptides cannot replace echocardiography safely $[21,22]$.

Perik et al. (2008) explored early, subclinical cardiac toxicity detected by NT-proBNP and troponin $\mathrm{T}$ in 55 patients with gastrointestinal stromal tumor (GIST) receiving the cardiotoxic drug imatinib [23]. In conclusion there was no association with cardiac toxicity and an increase in NT-proBNP levels.

The results of our study support these findings. We could not show any significant correlation between BNP or NT-proBNP and LVEF, on the one hand, and the combined endpoint, on the other. Nearly all values measured during the study period were within the normal range, independent of the progression of symptoms of heart failure as measured by NYHA stage or decline in LVEF. The hypothesis that the natriuretic peptides can predict cardiac dysfunction caused by cardiotoxic medication cannot be confirmed by the results of our study.

\section{Troponin}

Troponin is elevated in situations involving myocardial damage. It can be assumed that troponin I increases after cardiotoxic chemotherapy. In the present study analysis, cardiac troponin I levels were within the local limit of normal in all patients (cut-off for significant myocardial damage: $0.5 \mathrm{ng} / \mathrm{ml}$ ) without significant differences before, during, or 
Citation: Jungandreas K, Vogt A, Voigt W, Jordan K, Strauß HG, et al. (2014) Natriuretic Peptides and Troponin I do not Predict ChemotherapyInduced Cardiac Toxicity. J Cardiovasc Dis Diagn 2: 140. doi:10.4172/2329-9517.1000140

after chemotherapy. Other studies showed partly contradictory results. Mathew et al. (2001, 15 children receiving anthracyclines) and Soker et al. (2005, 31 children treated with doxorubicin) did not find a significant increase in troponin I related to a decrease in systolic heart function in different studies with children [24,25]. Perik et al. (2008) also showed stable cTnT levels (before and 1 and 3 months after the start of imatinib treatment) in a study with 55 GIST patients [23]. In a study with 30 patients receiving anthracyclines Missov et al. (1997) showed elevated troponin I with normal LVEF[26]. However, the studies of Cardinale et al. (2000, 204 patients; 2002, 211 high-risk breast cancer women) and Sandri et al. (2003, 179 patients) verified left ventricular dysfunction 1-3 months after treatment if an early and lasting increase in cardiac troponin I was observed [27-29]. Furthermore the magnitude of the troponin I values correlated with the degree of cardiac dysfunction. There is evidence that troponin I can be a useful marker for early detection of cardiotoxicity; however, our study results cannot support this role of troponin I.

\section{Echocardiography}

We studied different echocardiographic parameters. Three patients of our study population developed local mural movement disorder with normal LVEF. The differences in LVEF were low, that they did not reach the predefined endpoint like decrease in LVEF of 20 or $10 \%$. Similarly to Sawaya et al. (2011) it can be assumed that local movement disorders indicate the cardiac toxicity caused by cardiotoxic medication [22].

As mentioned above, Tei-index and TAPSE (tricuspid annular plane systolic excursion) did not show any significant relationship between the two groups of patients. Some diastolic parameters of echocardiography (E', A', E/E', and E/A) were evaluated in different studies. In a study of 26 patients treated with anthracyclines Pudil et al. $(2008)$ noticed a significant increase in the $A$-wave $(p<0.01)$ at 6 months and Ganame et al. (2007) a significant decrease in the E-wave in a study with 13 children receiving anthracyclines [30,31]. Both of them showed an increase in E/A in the early period of cardiac toxicity. As an early parameter of cardiac toxicity, we found an unchanged $\mathrm{E}$-wave and a significantly decreased A-wave $(\mathrm{p}=0.009)$ in the patients with cardiac injury. As a result we had a significantly lower E/A $(p=0.005)$ in the control group. For the other diastolic parameters ( $E$ ', $\left.\mathrm{E} / \mathrm{E}^{\prime}\right)$ no correlation was observed between the occurrence of cardiac injury and the early changing of these parameters. In general, there is a significantly higher occurrence of cardiac toxicity $(p<0.001)$ if a diastolic dysfunction (stage 2 ) is known before chemotherapy.

\section{Dyspnea}

Dyspnea is a typical symptom of chronic heart failure, but it has not been examined as an early sign of cardiac toxicity caused by chemotherapy. We found progressive dyspnea as defined by an increase of NYHA stage $\geq 1$ in 21 of 99 patients of this study during the 12-month study period. This was related to the decrease in LVEF with a negative predictive value of $91.0 \%(\mathrm{p}<0.001)$. With a positive predictive value of $42.9 \%$ it is not clear that cardiotoxic side effects are caused by chemotherapy in patients with dyspnea. Thus, the challenge is to find an objective means of employing the subjective sign dyspnea as a useful marker [32-37].

\section{Summary}

In the present study none of the established markers of cardiac insufficiency (BNP, NT-proBNP) or myocardial injury (troponin I) showed a significant correlation with cardiac toxicity at an early stage.
The most reliable parameter for the exclusion of a decrease in LVEF was stable clinical condition without an increase in dyspnea as defined by NYHA stage with a negative predictive value of $91.0 \%$.

\section{References}

1. Carver JR, Shapiro CL, Ng A, Jacobs L, Schwartz C, et al. (2007) American Society of Clinical Oncology clinical evidence review on the ongoing care of adult cancer survivors: cardiac and pulmonary late effects. J Clin Oncol 25 : 3991-4008.

2. Paulides M, Wojnowski L (2007) [Chemotherapeutics-induced heart failure] Med Klin (Munich) 102: 574-578.

3. Barrett-Lee PJ, Dixon JM, Farrell C, Jones A, Leonard R, et al. (2009) Expert opinion on the use of anthracyclines in patients with advanced breast cancer at cardiac risk. Ann Oncol 20: 816-827.

4. Pönisch W, Niederwieser D (2006) [Late effects after chemotherapy]. Internist (Berl) 47: 266-268, 270-72.

5. Oechsle K, Bokemeyer C (2009) Kardiotoxizitäten bei Chemo- und Radiotherapie. Onkologe 15: 157-162.

6. Lipp HP, Bokemeyer C (2005) [The action and toxicity of taxanes]. Pharm Unserer Zeit 34: 128-137.

7. Costa RB, Kurra G, Greenberg L, Geyer CE (2010) Efficacy and cardiac safety of adjuvant trastuzumab-based chemotherapy regimens for HER2-positive early breast cancer. Ann Oncol 21: 2153-2160.

8. Force T, Kerkelä R (2008) Cardiotoxicity of the new cancer therapeuticsmechanisms of, and approaches to, the problem. Drug Discov Today 13: 778784

9. Buck T, Breithardt O-A, Faber L, Fehske W, Flachskampf FA, et al. (2009) Manual zur Indikation und Durchführung der Echokardiographie. Clin Res Cardiol Suppl 4: 3-51.

10. Tissières P, Beghetti M (2008) Biomarker in der pädiatrischen Kardiologie. Paediatrica 19: 19-20.

11. Erbel R, Neumann T, Zeidan Z, Bartel T, Buck T (2002) [Echocardiography diagnosis of diastolic heart failure]. Herz 27: 99-106.

12. Meinardi MT, van Veldhuisen DJ, Gietema JA, Dolsma WV, Boomsma F, et al. (2001) Prospective evaluation of early cardiac damage induced by epirubicincontaining adjuvant chemotherapy and locoregional radiotherapy in breast cancer patients. J Clin Oncol 19: 2746-2753.

13. Nousiainen T, Vanninen E, Jantunen E, Puustinen J, Remes J, et al. (2002) Natriuretic peptides during the development of doxorubicin-induced left ventricular diastolic dysfunction. J Intern Med 251: 228-234.

14. Snowden JA, Hill GR, Hunt P, Carnoutsos S, Spearing RL, et al. (2000) Assessment of cardiotoxicity during haemopoietic stem cell transplantation with plasma brain natriuretic peptide. Bone Marrow Transplant 26: 309-313.

15. Germanakis I, Kalmanti M, Parthenakis F, Nikitovic D, Stiakaki E, et al. (2006) Correlation of plasma $\mathrm{N}$-terminal pro-brain natriuretic peptide levels with left ventricle mass in children treated with anthracyclines. Int J Cardiol 108: 212215

16. Koh E, Nakamura T, Takahashi $\mathrm{H}$ (2004) Troponin-T and brain natriuretic peptide as predictors for adriamycin-induced cardiomyopathy in rats. Circ $J$ 68: 163-167.

17. Sandri MT, Salvatici M, Cardinale D, Zorzino L, Passerini R, et al. (2005) $\mathrm{N}$-terminal pro-B-type natriuretic peptide after high-dose chemotherapy: a marker predictive of cardiac dysfunction? Clin Chem 51: 1405-1410.

18. Suzuki T, Hayashi D, Yamazaki T, Mizuno T, Kanda Y, et al. (1998) Elevated B-type natriuretic peptide levels after anthracycline administration. Am Heart $J$ 136: $362-363$.

19. Dodos F, Halbsguth T, Erdmann E, Hoppe UC (2008) Usefulness of myocardia performance index and biochemical markers for early detection of anthracyclineinduced cardiotoxicity in adults. Clin Res Cardiol 97: 318-326.

20. Pichon MF, Cvitkovic F, Hacene K, Delaunay J, Lokiec F, et al. (2005) Drug induced cardiotoxicity studied by longitudinal B-type natriuretic peptide assays and radionuclide ventriculography. In Vivo 19: 567-576.

21. Daugaard G, Lassen U, Bie P, Pedersen EB, Jensen KT, et al. (2005) Natriuretic 
Citation: Jungandreas K, Vogt A, Voigt W, Jordan K, Strauß HG, et al. (2014) Natriuretic Peptides and Troponin I do not Predict ChemotherapyInduced Cardiac Toxicity. J Cardiovasc Dis Diagn 2: 140. doi:10.4172/2329-9517.1000140

peptides in the monitoring of anthracycline induced reduction in left ventricular ejection fraction. Eur J Heart Fail 7: 87-93.

22. Sawaya H, Sebag IA, Plana JC, Januzzi JL, Ky B, et al. (2011) Early detection and prediction of cardiotoxicity in chemotherapy-treated patients. Am J Cardio 107: $1375-1380$

23. Perik PJ, Rikhof B, de Jong FA, Verweij J, Gietema JA, et al. (2008) Results of plasma N-terminal pro B-type natriuretic peptide and cardiac troponin monitoring in GIST patients do not support the existence of imatinib-induced cardiotoxicity. Ann Oncol 19: 359-361.

24. Mathew P, Suarez W, Kip K, Bayar E, Jasty R, et al. (2001) Is there a potential role for serum cardiac troponin $\mathrm{I}$ as a marker for myocardial dysfunction in pediatric patients receiving anthracycline-based therapy? A pilot study Cancer Invest 19: 352-359.

25. Soker M, Kervancioglu M (2005) Plasma concentrations of NT-pro-BNP and cardiac troponin-I in relation to doxorubicin-induced cardiomyopathy and cardiac function in childhood malignancy. Saudi Med J 26: 1197-1202.

26. Missov E, Calzolari C, Davy JM, Leclercq F, Rossi M, et al. (1997) Cardiac troponin I in patients with hematologic malignancies. Coron Artery Dis 8: 537541

27. Cardinale D, Sandri MT, Martinoni A, Borghini E, Civelli M, et al. (2002) Myocardial injury revealed by plasma troponin I in breast cancer treated with high-dose chemotherapy. Ann Oncol 13: 710-715.

28. Cardinale D, Sandri MT, Martinoni A, Tricca A, Civelli M, et al. (2000) Left ventricular dysfunction predicted by early troponin I release after high-dose chemotherapy. J Am Coll Cardiol 36: 517-522.

29. Sandri MT, Cardinale D, Zorzino L, Passerini R, Lentati $P$, et al. (2003) Minor increases in plasma troponin I predict decreased left ventricular ejection fraction after high-dose chemotherapy. Clin Chem 49: 248-252.

30. Pudil R, Horacek JM, Strasova A, Jebavy L, Vojacek J (2008) Monitoring of the very early changes of left ventricular diastolic function in patients with acute leukemia treated with anthracyclines. Exp Oncol 30: 160-162.

31. Ganame J, Claus P, Eyskens B, Uyttebroeck A, Renard M, et al. (2007) Acute cardiac functional and morphological changes after Anthracycline infusions in children. Am J Cardiol 99: 974-977. 